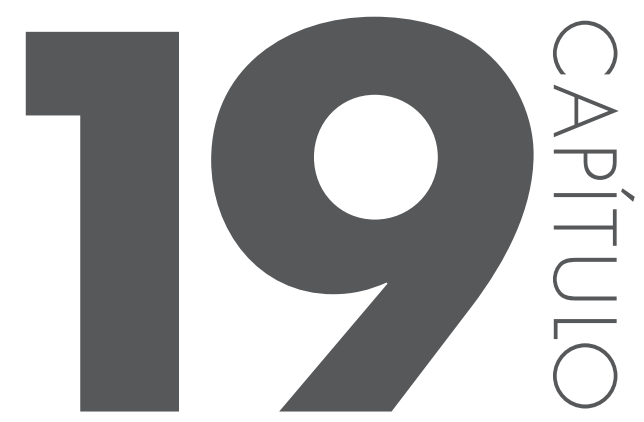

\title{
MAPEAMENTO DAS ÁREAS DE RISCO DOS ESPAC̣OS PERIFÉRICOS DA CIDADE DE CATALÃO (GO): O USO do Cadastro para identificar os riscos
}

MENDES, Pedro Paulo Mesquita ${ }^{1 *}$; ORLANDO, Paulo Henrique Kingma ${ }^{2}$

1 Geógrafo. Mestrando do Programa de Pós-graduação em Geografia da Universidade Federal de Goiás/Regional Catalão

2 Géografo. Professor do Programa de Pós-graduação em Geografia da Universidade Federal de Goiás/Regional Catalão

*email: pedropaulo.mendes@hotmail.com

\section{RESUMO}

O presente texto procura trazer algumas reflexões sobre a temática em torno do uso do cadastro para mapeamento das áreas de risco em perímetro urbano. A apresentação dos conceitos sobre cadastro e áreas de risco foi estabelecida segundo as definições por pesquisadores ou/e instituições públicas. Foram analisados, também, outros conceitos como vulnerabilidade e ameaça. De forma sintética, o presente artigo expõe uma classificação de risco. Quanto aos autores que trazem estas problematizações, foram consultados Guerra (2005); Botelho (2007); Chiristofoletti (1994); Macedo (1992); Castro (1998); Loch (1990); Silva (1979); Carpi Júnior (2005); 
Veyret (2013); Rabelo (2003); Cerri e Amaral (1998) IPT (2007) dentre outros, que buscam compreender as dinâmicas espaciais e ambientais de áreas de riscos, bem como os manuais do Ministério das Cidades, Ministério da Integração Nacional e os parâmetros da Defesa Civil. Diante disso, este artigo tem como objetivo apresentar a localização e implicação das áreas de risco do perímetro urbano no município de Catalão (GO). As áreas de risco escolhidas para a pesquisa estão em locais com menor valor imobiliário, próximas dos espaços periféricos da Cidade, compondo novas áreas de expansão da malha urbana. Para atender aos objetivos propostos, foram utilizados procedimentos e técnicas, como visitas técnicas aos locais vulneráveis a risco, revisão de literatura, uso de equipamento de georeferenciamento, ficha de cadastro e entre outros documentos. $\mathrm{O}$ interesse pela discussão da temática surgiu após perceber que a cidade de Catalão não possui estudos acadêmicos sobre risco e nem o Plano Municipal de Redução de Risco (PMRR).

Palavras-chave: Áreas de risco; Cadastro; Catalão (GO)

MENDES, Pedro Paulo Mesquita; ORLANDO, Paulo Henrique Kingma; "MAPEAMENTO DAS ÁREAS DE RISCO DOS ESPAÇOS PERIFÉRICOS DA CIDADE DE CATALÃO (G0): o uso do Cadastro para identificar os riscos", p. 307-323 . In: Seminário de Pesquisa, Pós- Graduação e Inovação da Regional Catalão (2. : 2014 : Goiás) Coletânea Interdisciplinar em Pesquisa, Pós- Graduação e Inovação - Volume 1 : Estudos Ambientais, Território e Movimentos Sociais. Anais [livro eletrônico] / organizado por Adriana Freitas Neves, Idelvone Mendes Ferreira, Maria Helena de Paula, Petrus Henrique Ribeiro dos Anjos. São Paulo: Blucher, 2015. ISBN: 978-85-8039-109-1, DOI 10.5151/9788580391091-V1_Cap19 


\section{INTRODUC̣ÃO}

O controle ambiental urbanístico têm sido um dos grandes problemas mundiais a ser enfrentado pelos administradores, planejadores e usuários do espaço ocupado pelas cidades e suas áreas adjacentes. No Brasil, a concentração urbana é da ordem de $80 \%$ do total da população humana. Essa concentração urbana pode ser caracterizada pela expansão irregular das periferias, com pouca observação às regulamentaçoes urbanas estabelecidas num plano diretor ou às normas específicas de loteamentos, ocorrendo, sistematicamente, ocupação irregular de áreas públicas e/ou privadas por contingente populacional, na sua maioria de baixa renda.

Dessa forma, a um conjunto de eventos trágicos, passiveis de ocorrer principalmente no período de chuvas, que se reproduzem em acidentes de características semelhantes em áreas urbanas de risco em todo País, como inundações de vales, instabilidade de encostas e ocorrência de processos erosivos, entre outros eventos associados ao risco hidrológico, geológico e atmosférico. No período da seca o risco está associado à queimadas de vegetações localizadas dentro ou próxima às cidades. A ocorrência desses eventos, no perímetro urbano, é tratada como sendo áreas de risco e essencialmente de forma emergencial pelos Sistemas de Defesa Civil, inexistindo na quase totalidade de municípios brasileiros.

Para que ações preventivas sejam aplicadas em áreas de risco é necessário identifica-las, cadastra-las e estudar suas dinâmicas.Um sistema decadastramento de áreas urbanas de risco implica, em primeiro lugar, no conhecimento do problema por meio do mapeamento dos riscos, sendo que essas áreas, caracterizadas em seus diferentes níveis de risco, devem ser hierarquizadas para o estabelecimento de medidas preventivas e/ou corretivas, e administradas por meio de ações de controle de uso e ocupação do solo. Diante disso, este artigo tem como objetivo apresentar a localização e implicação das áreas de risco na malha urbana do município de Catalão $(\mathrm{GO})$, através de recurso de 'Ficha de Cadastro', recurso tecnológico de georeferenciamento e visitas técnicas aos locais vulneráveis ao risco.

Para atender aos objetivos propostos, utilizou-se de procedimentos e técnicas, como; ida a campo, revisão de literatura, uso de equipamento de georeferenciamento, entre outros. Dentre esses procedimentos metodológicos, foram utilizados: a) pesquisa teórica sobre cadastro e área de risco; b) a pesquisa documental feita a partir da análise de documentos censitários do IBGE, dos mapas e plantas constantes no Plano Diretor do munícipio Catalão (GO), dos Relatórios da $11^{\text {a }}$ Regional Estadual de Defesa Civil, e do Plano Local 
de Habitação de Interesse Social de Catalão (GO) - (PLHIS); c) a pesquisa de campo foi realizada através da aplicação de Roteiros de Cadastro, observação não-estruturada, registro fotográfico e coletas dos pontos georeferrenciadas através do Global Positioning System - GPS.

A compreensão da dinâmica dessas áreas de risco sugere ultrapassar a perspectiva que contrapõem planejamento e uso e ocupação do solo e também permite a leitura de realidades que não se ajustam em modelos prontos para ocorrência de desastres destas localidades. Compreende-las, significa desvendar a interligação de eventos naturais e antrópicos de forma desarmoniosa, que ao realizar-se, pode ocorre perdas de vidas e bens matérias. Acredita-se que, na cidade, a relação entre uso e ocupação do solo, o aumento populacional humano e as condições ambientais, pode ser compreendidas por meio de uma analise das áreas degradadas, aos quais influenciam diretamente na configuração do lugar.

\section{O CADASTRO ENQUANTO INSTRUMENTO PARA MAPEAMENTO DE ÁREAS DE RISCO: VIDAS EM RISCO}

O debate acadêmico em torno das interpretações dos eventos naturais ou antrópicos que implicam perdas de vidas e/ou bens matérias em áreas vulneráveis a risco se renova a partir de cada grande novo desastre e/ou catástrofe. Novos estudos sobre riscos naturais, como deslizamento, inundações, erosões, assoreamento de rios, tempestades, enchentes, doenças virais e bacterianas, entre outros eventos, devem realizar-se em face a essas novas abordagens, pois é ao entender o natural e o antrópico como parte de um mesmo processo que se reconhecerá o possível surgimento de áreas de risco.

Um fator a ser considerado no estudo sobre áreas de risco é o fato de reconhecer as estações climáticas do ano como parte condicionante do aumento ou diminuição de eventos desastrosos, sendo que alguns eventos ocorrem independentemente de períodos chuvosos ou secos. Visto que, algumas áreas de riscos aumenta sua potencialidade ou surge em conjunto com práticas humanas e eventos naturais, porém a área de risco é só considerada com a presença do homem. Por isso que, o cadastro destas áreas é uma ferramenta auxiliadora do gerenciamento e acompanhamento de possíveis riscos.

Além disso, buscam-se estudos e interpretações de áreas de riscos que vão além da abrangência do meio físico e que se compreenda que as condicionantes do surgimento de áreas de riscos perpassam também por aspectos culturais, políticas e sociais. Diante dessas considerações, e ao buscar investigações que 
contemplem novas leituras sobre risco que permitam analisar a inter-relação do cadastro de áreas de riscos, é que pode-se pensar um gerenciamento das mesmas.

Fatores econômicos, políticos, sociais e culturais contribuem para o avanço e a perpetuação do quadro indesejável das áreas de risco. Segundo o IPT (2007) o problema das áreas de risco nas cidades brasileiras pode ser sintetizado, conforme descrito a seguir:

Crise econômica e social com solução a longo prazo; Política habitacional para baixa renda historicamente ineficiente; Ineficácia dos sistemas de controle do uso e ocupação do solo; Inexistência de legislação adequada para as áreas suscetíveis aos riscos mencionados; Inexistência de apoio técnico para as populações; Cultura popular de "morar no plano". (IPT, 2007, p. 15 - grifo do autor)

Com isso, a existência de um cadastro das áreas de risco é tida como sendo uma ferramenta necessária para o Plano Municipal de Redução de Risco (PMRR). Através do PMRR pode-se gerar ações preventivas ou iniciar o gerenciamento das áreas de risco. O objetivo maior de um PMRR é o de erradicar, controlar e/ ou reduzir as situações de risco associadas à dinâmica superficial e que coloca em perigo a vida e os bens materiais da população humana e demais outros seres vivos inseridos nestas áreas, sendo um instrumento de gestão urbana de fundamental importância para o controle e mitigação dos riscos nas cidades brasileiras.

Contudo, o cadastro pretende pelo menos a homogeneização da coleta dos dados, manutenção de arquivos, que podem se transformar em bancos de dados e possibilitar uma análise histórica dos eventos, identificando a sua potencialidade de risco, sua classificação e a sua provável origem. O cadastramento também é uma ferramenta auxiliar para o monitoramento.

Existem vários exemplos de cadastro para áreas de risco. Macedo (1992) publicou o cadastramento de riscos de escorregamentos em área da cidade de Guaratinguetá (SP). Este cadastramento permitiu a distribuição do risco em uma planta do bairro e o estabelecimento de prioridade de atuação por parte da Prefeitura Municipal.

O IPT (1996) realizou zoneamento de risco de escorregamento em área de risco no município de Jundiaí (SP) e utilizou uma ficha de vistoria de campo. Em outro trabalho, o IPT (1992) apresentou um cadastramento de área de baixa renda sujeita a movimento de massa tipo escorregamento de cortes e realizado 
em São Sebastião (SP). Já Martins (2005), na sua Dissertação de Mestrado sobre "Cadastro Georreferenciado de Erosões no Distrito Federal" identifica 1.252 áreas com indícios a ocorrência de feições erosivas que podem implicar área de risco.

Segundo Silva (1979) o cadastro deve ser entendido como um registro na forma descritiva e na forma cartográfica. A parte descritiva do Cadastro, além de atender às necessidades informacionais das áreas de riscos, deve servir como um banco de dados para todos os órgãos de interesse público que necessitam desta classe de informação, como exemplo, as Secretaria de Habitação, do Meio Ambiente, de Obras e da Defesa Civil. A parte cartográfica do Cadastro trata da localização e da dimensão do risco. É, pois, a ferramenta básica para trabalhos dos planejadores e dos gestores públicos.

Portanto, para que se possa implementar o cadastramento de áreas de riscos, deve-se levar em conta, de acordo com Silva (1979), que Cadastro é uma matéria multidisciplinar que envolve conhecimentos de direito, levantamentos (terrestres ou aéreos), administração e planejamentos estratégicos. Em função do volume de dados envolvidos no processo, este poderá ser automatizado, englobando também conhecimentos da área de processamento de dados. Desse modo, sendo o Cadastro uma matéria multidisciplinar, exige para tal fim, a contribuição de pessoal especializado nos mais diversos ramos do conhecimento técnico-cientifico.

Assim, o cadastramento de áreas de riscos constitui o primeiro passo para para prevenção, gerenciamento e recuperação das mesmas, tendo como objetivo diagnosticar cada uma das áreas ${ }^{1}$, registrando em ficha de cadastro apropriada, e as qualifica quanto ao seu nível de risco. O Cadastro dos Riscos proporciona um avanço no conhecimento do comportamento das áleas e suas relações com espaço, uma vez que um dos objetivos do Cadastro é, também, destacar a dinâmica das áreas de riscos.

A discussão sobre riscos e, especialmente, sobre riscos de desastres, tem se tornado cada vez mais constante no nosso contexto social. Trata-se de um dos principais conceitos em defesa civil, pois localiza a reflexão sobre as ações que podem ser empregadas antes da ocorrência do desastre. Denomina-se risco de desastre a probabilidade de ocorrência de um evento adverso, causando danos ou prejuízos. Convencionalmente, o risco é expresso pela fórmula: Risco = Ameaça x Vulnerabilidade.

Para que esta fórmula seja compreendida deve-se saber o conceito de cada variável. O significado do risco discorrendo como o mesmo surgiu na nossa sociedade e se apresenta até os dias atuais. 
O termo "risco" origina-se do latim resecum, "o que corta", derivado do verbo resecare, "ato de dividir, cortar separando". Designava o estilete empregado pelos romanos para marcar as tabuletas de cera que eram usadas para escrever antes da adoção do papiro. Mais tarde, na época medieval, em linguagem náutica, riscum veio a significar "penhasco", "perigo no mar", "perigo oculto", o que poderá explicar o conceito estabelecido na teoria epidemiológica. (ALMEIDA-FILHO, 2008, p. 5 - grifos do autor).

No Brasil, em 2006, o Ministério das Cidades adotou o conceito de risco como "Relação entre a possibilidade de ocorrência de um dado processo ou fenômeno e a magnitude de danos ou conseqüências sociais elou econômicas sobre um dado elemento, grupo ou comunidade." (MINISTÉRIO DAS CIDADES, 2006, p. 3).

Cerri e Amaral (1998) estipularam uma classificação do risco na concepção ambiental, considerados de maior risco, com destaque para o risco geológico, um dos mais ocorrentes que pode ser observado no ambiente urbano, como mostra a Figura 1.

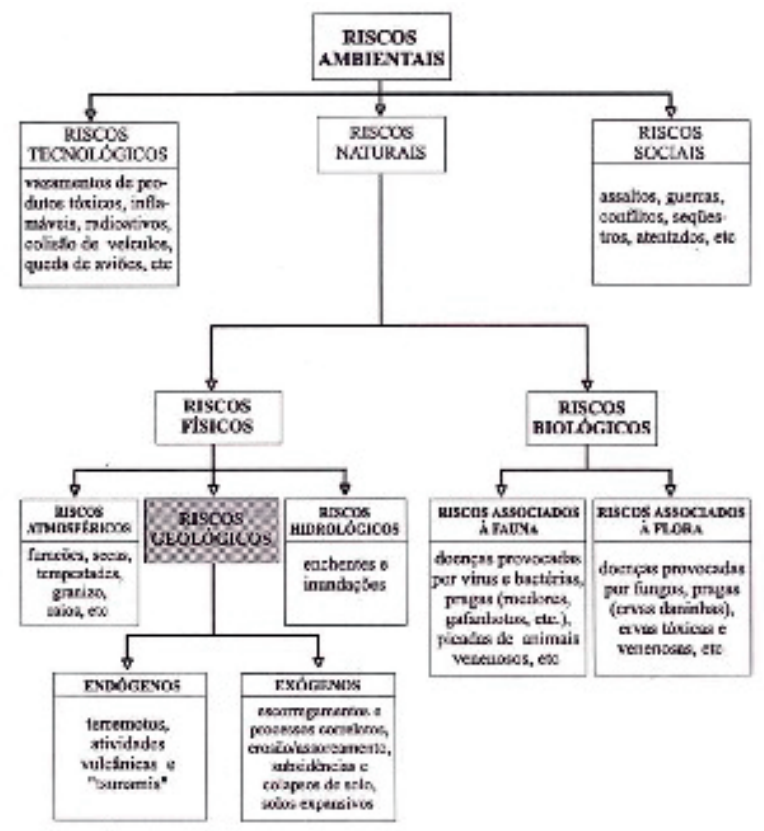

Figura 1 - Classificação dos risco

Fonte: Cerri e Amaral (1998). 
Há inúmeras formas de classificar os riscos. Uma delas, tendo por base situações potenciais de perdas e danos ao homem, considera os riscos ambientais como a classe maior dos riscos, subdividindo-os em classes e subclasses [...]. Já os riscos geológicos são classificados em riscos endógenos (associados aos processos da geodinâmica interna) e riscos exógenos (geodinâmica externa). (CERRI; AMARAL, 1998, p. 301-303).

Porém a noção de vulnerabilidade, que se associa à de risco, tem sido também matéria de discussão, com destaque para as considerações realizadas por Rebelo (2003, p. 252) quando afirma que existe uma confusão entre os termos utilizados para tratar de riscos e vulnerabilidades.

Tradicionalmente, a Defesa Civil compreende o conceito de vulnerabilidade como "[...] condição intrínseca ao corpo ou sistema receptor que, em interação com a magnitude do evento ou acidente, define os efeitos adversos, medidos em termos de intensidade dos danos previstos" (CASTRO, 1999, p. 9)

O grau de vulnerabilidade seria medido em função da intensidade dos danos e da magnitude da ameaça. Fundamental, no entanto, é refletir sobre quais são essas condições que fragilizam uma dada população, bairro ou pessoa; de que maneira essas condições se constituem e se inter-relacionam e, ainda, são mantidas em nossa sociedade; entender quais são as metodologias disponíveis para identificar e avaliar as diferentes dimensões que compõem a vulnerabilidade a desastres; e quais as estratégias e ações que devem ser implementadas para reduzir a vulnerabilidade da área.

A última variável da fórmula - a ameaça, é definida pelo Glossário de Defesa Civil e Estudos de Riscos e Medicina de Desastres como sendo: "1. Risco imediato de desastre. Prenúncio ou indício de um evento desastroso. Evento adverso provocador de desastre, quando ainda potencial. 2. Estimativa da ocorrência e magnitude de um evento adverso, expressa em termos de probabilidade estatística de concretização do evento (ou acidente) e da provável magnitude de sua manifestação.”

Diante dessas considerações, note-se que cresce no Brasil, em especial nos estudos de controle ambiental urbanístico e na Ciência Geográfica, o interesse de pesquisadores por temas que discutam sobre: a) ferramenta auxiliadora, os cadastros, para gerenciamento das áreas de risco; b) as medidas mitigadoras para contenção ou prevenção de desastres; c) os efeitos do uso e ocupação do solo nas áreas urbanas que implicam desastres. d) elaboração de conceitos precisos sobre risco, vulnerabilidade e ameaças. 


\section{DINÂMICA ESPACIAL, FITOGEOGRÁFICA E A LOCALIZAÇÃO DO PERÍMETRO URBANO DE CATALÃO (GO)}

Para a realização dos estudos, os dados foram extraídos da Superintendência de Estatística, Pesquisa e Informação (SEPIN), órgão da Secretaria do Planejamento e Desenvolvimento do Estado de Goiás (SEPLAN-GO); do Banco de Dados Estatísticos de Goiás (BDE-GO); de estimativas e Censos Populacionais do Instituto Brasileiro de Geografia e Estatística (IBGE); do Atlas do Desenvolvimento Humano no Brasil do Programa das Nações Unidas para o Desenvolvimento (PNUD); além de outras fontes, como a própria Prefeitura Municipal de Catalão.

O município de Catalão foi formalmente constituído em 20 de agosto de 1859, embora sua ocupação tenha se dado já na primeira metade do século XVIII. As características e localização da área de pesquisa não existem em vários campos científicos, porem, na Geografia, adquire importância considerável. Nesse sentido, a área foi localizada, delimitada e caracterizada de acordo com seus aspectos sociais, econômicos, espaciais, culturais, ambientais, entre outros aspectos.

A área escolhida para a realização da pesquisa foi o município de Catalão, Estado de Goiás. A Microrregião de Catalão integra-se a Mesorregião do Sul Goiano (IBGE, 1990), estando compreendido entre os meridianos de $47^{\circ} 17 \mathrm{e}$ $48^{\circ} 12^{\prime}$ Longitude W Grt e os paralelos $17^{\circ} 28^{\prime}$ e $18^{\circ}$ Latitude S, abrangendo uma área de $3.778,6 \mathrm{~km} 2$ (IBGE, 2010), correspondendo a 1,11\% do território Goiano, conforme demonstra a Figura 2. Em seu contexto socioespacial, o

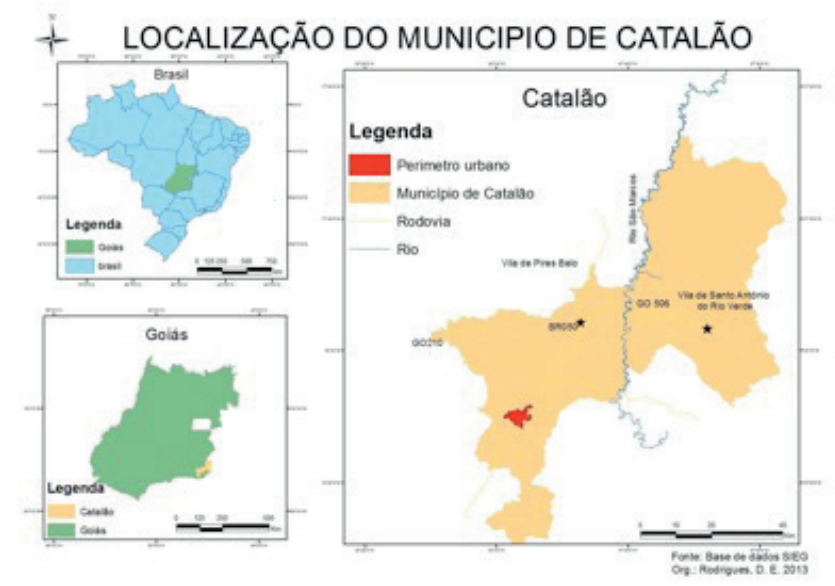

Figura 2 - Localização do município de Catalão (G0) - 2013. 
município de Catalão possui quatro povoados: Olhos D’agua, Pedra Branca, Cisterna e Martírios, e dois Distritos: Santo Antônio do Rio Verde e Pires Belo. O Município conta com um total de 75.623 habitantes, sendo que 70.212 dos habitantes residem na zona urbana, o que corresponde a $92,84 \%$ da população humana total, enquanto apenas 5.411 habitantes residem na zona rural, corresponde a 7,16\% (IBGE, 2010).

A Sede do Município esta distante cerca de $100 \mathrm{~km}$ de Uberlândia (MG), interligada pela rodovia BR-050, 258km de Goiânia, Capital do Estado de Goiás, pela rodovia GO-330 e a $305 \mathrm{~km}$ de Brasília (DF), pela rodovia BR050 e, ainda, pela GO-352 as interliga as cidades de Goiandira e Corumbaíba. Possui um Distrito Minero-Industrial (DIMIC), com empresas mineradoras de beneficiamento e processamento de nióbio (Copebrás S.A - Grupo Anglo American) e fosfato (Mineração Catalão - Grupo Anglo American e Vale Fertilizante). Com duas montadoras, John Deere (Cameco do Brasil), montadora de colheitadeiras de algodão e cana, e a Mitsubishi Motores Corporation, montadora de veículos automotores.

Nos aspectos geofísicos destaca-se na área urbana da cidade de Catalão a declividade como um fator importante na área Leste onde existem as nascentes do Córrego Santo Antônio. As casas se aproximaram muito destes locais e não podem avançar a ocupação deste local. As declividades encontradas no relevo da bacia hidrográfica deste Córrego são muito grandes. Uma ocupação urbana no interior desta bacia hidrográfica poderia trazer muitos problemas ambientais, urbanos e até mesmo de risco as estruturas que fossem construídas neste local.

A outra bacia hidrográfica na qual a Cidade está situada é a Bacia Hidrográfica do Córrego Pirapitinga. Ela abrange a maior parte da área da malha urbana e possui várias nascentes. As principais foram representadas e atualmente constituem um conjunto de barragens ao longo de todo do Alto Curso do Córrego. Isto constituiu, para aquelas represas situadas no interior da malha urbana, um local de lazer e de espaços verdes para todos os habitantes. Por outro lado é preciso estabelecer um monitoramento contínuo de todas as barragens para que, no período de chuvas, não exista a possibilidade de uma delas sofres danos em sua estrutura e provocar uma inundação na Cidade e os impactos decorrentes.

É preciso garantir também que a vazão do Córrego Pirapitinga e de seus afluentes no período chuvoso não ultrapasse a capacidade da calha da rede de drenagem, evitando-se enchentes, inundações que possam afetar a circulação das pessoas e também as moradias.

$\mathrm{Na}$ área urbana consolidada, o Córrego Pirapitinga foi canalizado e foi 
construída uma avenida ao lado de suas margens que ainda não foi totalmente ocupada, mas não possui área de preservação permanente com cobertura vegetal, pois sua vegetação natural já foi suprimida. O uso do solo no entorno dessa avenida (Av. Raulina Fonseca Pascoal) e também do entorno dos demais Córregos que ainda não foram urbanizados deveria se dar no sentido da formação e preservação de coberturas vegetais naturais, como bosques para evitar a impermeabilização do solo, e, no futuro, a ocorrência de enchentes que possam atingir moradias e que também influenciam na ocorrência de processos erosivos, aumentando os impactos decorrentes de processo de intervenção.

\section{RESULTADO E ANÁLISE DA PESQUISA: OS RISCOS NO ESPAC̣O PERIFÉRICO}

As áreas de risco escolhidas para a pesquisa são em locais com menor valor imobiliário, próximas dos espaços periféricos da Cidade, compondo novas áreas de expansão da malha urbana. Esta situação foi resultante da forma inadequada de parcelamento do solo urbano e da ausência de ação do Poder de Polícia Administrativa do Estado na fiscalização e autorização de obras que ocorreram nas últimas décadas.

Foram identificadas quatro áreas como assentamentos precários na Cidade, são eles: Bairros Pontal Norte, Dona Sofia e Aeroporto, Bairro Erondina e uma área próximo ao IBAMA no Bairro Santa Rita. Essas áreas foram identificadas através do uso de imagens de satélite no Programa Google Earth e também foram realizadas visitas a campo nesses locais delimitados a fim de promover a visualização e caracterização do local (Figura 3).

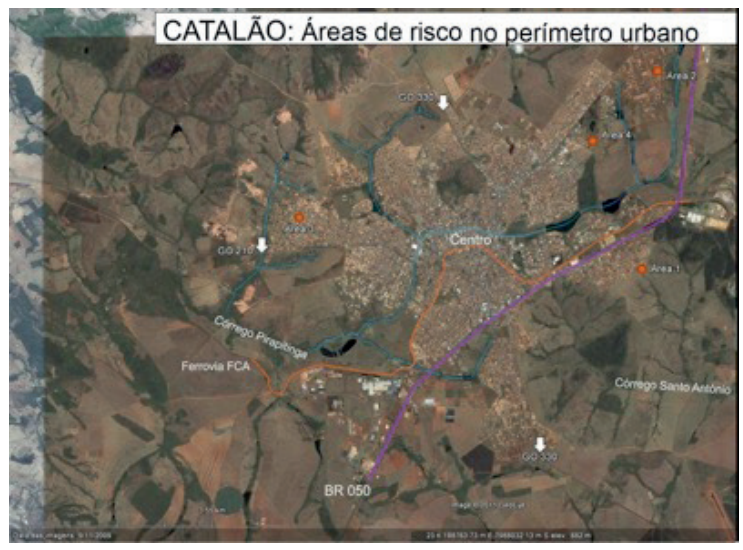

Figura 3 - Localização das áreas de risco

Fonte - Google Earth, 2009 - Equilibrio Consultoria (2011). Org. Mendes. P. P. M. (2014). 
A Área 1 está localizada na porção leste da Cidade. Devido à expansão da malha urbana, o Bairro Pontal Norte está localizado além da rodovia BR 050, o que provoca um isolamento da população desse Bairro em relação aos demais bairros da Cidade. Esse Bairro possui uma ocupação recente e seu crescimento está limitado por um atributo natural que é formado por um vale, no qual as declividades das vertentes, principalmente aquelas próximas a nascentes é muito grande, o que impede a construção e urbanização além das áreas que já estão ocupadas.

Trata-se então de uma área de risco não consolidável que implica no reassentamento total das moradias localizadas em seu interior. $\mathrm{O}$ número de moradias nessa área foi calculado com base nas visitas a campo e correlação as imagens do Software Google Earth para a área, sendo estimadas 11 moradias sob condições de risco.

A Área 2 compreende um conjunto de moradias situadas nos Bairros Aeroporto e Dona Sofia, com ocupação muito recente, que remonta a uma década, em uma área da periferia da Cidade, sendo também um espaço de expansão urbana. Trata-se de uma área que apresenta falta de infraestrutura e é resultado de um processo de invasão de áreas de propriedade do Município, consistindo também em irregularidade fundiária. O número de moradias nesta área foi calculado com base nas visitas a campo e correlação as imagens do Software Google Earth para a área, sendo estimado em 68 moradias sob condições de risco.

A Área 3 está localizada a oeste do centro da Cidade nos Bairros Erondina e Paraíso. A área de risco compreende uma faixa onde está localizada uma linha de transmissão de energia elétrica de alta tensão, sob a qual foram construídas casas nos últimos anos. O principal problema nesse setor é o consequente risco que as moradias correm por estarem praticamente embaixo da rede de transmissão de energia. Os Bairros Erondina e Paraíso também são recentes e constituem um eixo de expansão da cidade de Catalão. A rede de transmissão de energia foi instalada antes do loteamento e abastece a subestação de energia elétrica de Catalão. Ela pertence à CELG e possui uma tensão de $138 \mathrm{kV}$. A faixa de domínio é contada a partir de 16 metros a partir do eixo central da linha de transmissão, conforme dados da CELG. A Área 3 é, portanto, considerada como não consolidável. O número de moradias nesta área foi calculado com base nas visitas a campo e correlação as imagens do Software Google Earth para a área, sendo estimado em 47 moradias sob condições de risco.

A Área 4 está localizada na porção leste da Cidade. Sua ocupação também é resultado de irregularidade fundiária. Trata-se de uma pequena área, em uma rua que sofre as consequências da falta de infraestrutura presente nos bairros 
vizinhos da área que não possuem uma rede de drenagem pluvial. As moradias que estão no final da Rua Goiandira e início da Rua Geraldo B. da Silva estão localizadas em um terreno que fica abaixo do nível da barragem de uma represa localizada no interior da Unidade do IBAMA, entre os Bairros Santa Rita e Ipanema.

Durante o período chuvoso, as águas pluviais que correm a partir do Bairro Ipanema, que não possui drenagem pluvial, direcionam seu escoamento para a Lagoa Paquetá. Por sua vez, está lagoa já apresentasse com níveis consideráveis de assoreamento e degradação de sua área ripária. Com a diminuição da capacidade de armazenamento da água, provocado pelo assoreamento da lagoa com diversos materiais, a água transborda em direção as Ruas Goiandira e Geraldo B. Silva, sendo quando inundam as moradias que estão localizadas nesta área de risco, constituindo, assim, o principal problema desse local. A Área 4 é, portanto, considerada como consolidável mediante urbanização complexa. $\mathrm{O}$ número de moradias nesta área foi calculado com base nas visitas a campo e correlação as imagens do Software Google Earth para a área, sendo estimado em 28 moradias sob condições de risco.

\section{CONSIDERAC̣ÕES FINAIS}

Considerando que o objetivo central deste artigo é demonstrar a aplicabilidade do cadastro para o mapeamento das áreas de risco, especificamente os entornos do perímetro urbano da cidade de Catalão (GO) que ocorreram ausência de ação do Poder de Polícia Administrativa do Município na fiscalização e autorização de obras. Em toda a margem do perímetro foi possível constatar quatro áreas que podem ser classificadas como sendo de risco a integridade física e ao patrimônio do cidadão. Algumas áreas já estão consolidadas e outras em processo de consolidação. Através da visita a campo e por meio do uso de imagem de satélite constatou-se que aproximadamente 154 moradias estão na zona de risco. Das quatro áreas, duas áreas são vulneráveis a inundações, uma a processos geomorfológicos (terreno declivoso) e uma por rede elétrica de alta tensão.

Para que se possa ter uma visão total da situação das áreas de risco na cidade de Catalão (GO), a aplicação da ferramenta 'cadastro' deve ser levada para outras localidades, como por exemplo: Centro, áreas consolidadas e o Setor Industrial. Outros riscos devem ser incluídos no processo de observação, como o risco social, industrial e químico. Também, a construção de uma tabela/ quadro para acompanhamento do potencial de risco ao longo de cada estação 
climática do ano. Posteriormente formular um projeto planificado a ser entregue as instituições públicas competentes para que possa justificar a elaboração e implementação do Plano Municipal de Redução de Risco (PMRR) para o município de Catalão, base fundamental para evitarem-se possíveis tragédias ambientais. 


\section{Abstract}

This paper tries to give some reflections on the subject around the use of the registry for mapping of risk areas within the city limits. The presentation of the concepts of registration and risk areas was set according to the definitions by researchers and / or public institutions. Were also analyzed other concepts such as vulnerability and threat. Also, in summary form, this article presents a risk rating. As for the authors who bring these problematizations, War (2005) were consulted; Botelho (2007); Chiristofoletti (1994); Macedo (1992); Castro (1998); Loch (1990); Silva (1979); Carpi Junior (2005); Veyret (2013); Rabelo (2003); Cerri and Amaral (1998) IPT (2007) and others who seek to understand the spatial and dynamic areas of environmental risks as well as the manuals for the Ministry of Cities, Ministry of National Integration and the parameters of Civil Defense. Therefore, this article aims to show the location and implication of risk areas of urban perimeter of the city of Catalan (GO). Risk areas chosen for the study are in places with lower housing, close to the peripheral areas of the city, making up new areas for expansion of the urban grid value. To meet the objectives, procedures and techniques as were used; technical visits to locations vulnerable to risk, literature review, use of equipment georeferencing, registration form and others. Interest in the discussion of the theme came after realizing that the city of Catalan $(\mathrm{GO})$ is not academic studies on risk and neither the Municipal Plan Risk Reduction (PMRR).

Keywords: Risk áreas. Register. Catalão (GO). 


\section{REFERÊNCIAS}

AB'SABER, A. N. Um conceito de Geomorfologia a serviço das pesquisas sobre o Quaternário. In: Geomorfologia, Instituto de Geografia da Universidade de São Paulo, n.18, 1969.

ASSOCIACÃ̃O BRASILEIRA DE NORMAS TÉCNICAS. NBR 6023: informaç̃ão e documentaç̦ão: referências: elaboraç̃ão. Rio de Janeiro: ABNT, 2002.

NBR 6023: informaç̃ão e documentaç̦ão: referências: elaboraç̃̃o. Rio de Janeiro: ABNT, 2002.

NBR 15287: informacãa e documentação: projeto de pesquisa: apresentação. Rio de janeiro: ABNT,

2005.

ABGE. Riscos e acidentes: especialistas opinam sobre tragédias. Revista ABGE - Associação Brasileira da Geologia da Engenharia, São Paulo, n. 85, jul. ago.set. 2009.

ALCAZAR, M. G.; Catastro, propiedad y prosperidad. Jaeén - Espanha: Publicaciones de la Universidad de Jaén, 2007.

ALMEIDA-FILHO, N. 0 futuro do conceito de risco. Salvador: Instituto de Saúde Coletiva - Universidade Federal da Bahia, 2008.

BRASIL. Manual de desastres humanos: desastres humanos de natureza tecnológica Brasilia: Ministério da Integração Nacional. Secretaria Nacional de Defesa Civil, 2003 vla. Disponível em: <www.integracao.gov. br/c/document_library/get_file?uuid=879047d7-789e-4a7c-ae24-a8 lbeb48aecc\&groupld=10157> Acesso em: 01 de nov. de 2014.

BRASIL. Ministério da Integração Nacional. Secretaria Nacional de Defesa Civil. Glossário de Defesa Civil, estudos de riscos e medicina de desastres. 3. ed. Brasilia: MI, 2009.

CASTRO, A. L. C. Manual de desastres naturais. Brasilia: Ministério do Planejamento e Orçamento, Secretaria Especial de Políicas Regionais, Departamento de Defesa Civil,1996.

Manual de Planejamento em Defesa Civil. Brasilia: Ministério da Integração Nacional, Secretaria de Defesa Civil, 1999a. v.1.

Manual de Planejamento em Defesa Civil. Brasilia: Ministério da Integracãa Nacional, Secretaria de Defesa Civil, 1999b. v.3.

Manual de Planejamento em Defesa Civil. Brasilia: Ministério da Integração Nacional, Secretaria de Defesa Civil, 1999c. v.4.

2000.

Segurança global da população. Braślia: Ministério da Integração Nacional, Secretaria de Defesa Civil,

CASSETI, V. Ambiente e apropriação do relevo. São Paulo: Contexto, 1991. 147p.

CERRI, L. E. da S. ; AMARAL, C. P. do. Riscos geológicos. Geologia de Engenharia. São Paulo: Associação Brasileira de Geologia de Engenharia, 1998.

CEPED. UFSC. Capacitação básica em defesa civil: livro texto para educação à distância. Florianópolis: CEPED UFSC, 2011.

CHRISTOFOLETTI, A. Aplicabilidade do conhecimento geomorfológico nos projetos de planejamento. In: GUERRA, A. T.; CUNHA, S. B. (Org.). Geomorfologia: uma atualização de bases e conceitos. Rio de Janeiro: Bertrand Russel, 1994. p. 415-441. 
GUERRA, A. J. T.; BOTELHO, R. G. M.. Erosão dos solos. In: CUNHA S.B. da; A. J. T. GUERRA (Orgs.). Geomorfologia do Brasil. Rio de Janeiro: Bertrand Brasil, 1998. p. 181-227

$\therefore$ A. J. T.; MARCLLL, M. S. Geomorfologia Ambiental. Rio de Janeiro, Bertrand Brasil, 2006. p. 13-91 ; SILVA, A. S.; BOTELHO, R. G. M. (Orgs.) Impactos ambientais urbanos no Brasil. Rio de Janeiro: Bertrand Brasil, 2011. 418p.

GUILAM, M. C. R. 0 conceito de risco: sua utilização pela epidemiologia, engenharia e Ciências Sociais. 1996. Dissertação (Mestrado) - Universidade Estadual do Rio de Janeiro, 1996. Disponivel em: < www.ensp.fiocruz.br/ projetos/esterisco >. Acesso em: 29 out. 2014.

INSTITUTO BRASILEIRO DE GEOGRAFIA E ESTATISTICA. Censo 2010. Disponívelem:_www.ibge.gov.br/home/ estatistica/populacao/censo2010/G02010.pdf?. Acesso em: 01 de nov. de 2014.

IPT - Instituto de Pesquisas Tecnológicas do Estado de São Paulo. Orientaçães

para o combate à erosão no Estado de São Paulo, Bacia do Peixe - Paranpanema. Vol.6.

(IPT. Relatório, 24.739), (CP; ME), São Paulo, 1986.

. Controle de Erosão. Bases conceituais e técnicas; Diretrizes para o planejamento urbano e regional; Orientação para o controle de bocorocas urbanas. Governo do Estado de São Paulo, São Paulo. 1990.

MINISTÉRIO DAS CIDADES. SECRETARIA DE PROGRAMAS URBANOS. Capacitação em mapeamento e gerenciamento de risco: curso de capacitação. Braślia, 2006.

- Gestão e mapeamento de riscos socioambientais: curso de capacitação. Braślia: Ministério das Cidades, 2008.

SEDEC/Ministério da Integração. Política Nacional de Defesa Civil. Brasilia: MI, 2007.

. Portaria n. 117, de 7 de março de 2012. Anexo VIII - DOU de 09/03/2012 - Seção I. p. 30, 2012.

REBELO, F. Riscos naturais e acção antrópica. Coimbra: Imprensa da Universidade, 2003.

. Uma experiência européia em riscos naturais. Coimbra: Minerva Coimbra, 2005.

VEYRET, Y. (Org.). Os riscos: o homem como agressor e vítima do meio ambiente. São Paulo: Contexto, 2007.

; MESCHINET DE RICHEMOND, N. 0 risco, os riscos. In: VEYRET, Y. (Org.). Os riscos: o homem como agressor e víitima do meio ambiente. São Paulo: Contexto, 2007. p. 23-79. 
Seminário de Pesquisa, Pós-Graduacãoo e Inovação da Regional Catalão 